\title{
A PARTICIPAÇÃO DOS INVESTIMENTOS CHINESES NO PROCESSO DE REESTRUTURAÇÃO DO TERRITÓRIO FLUMINENSE \\ THE PARTICIPATION OF CHINESE INVESTMENTS IN THE PROCESS OF RESTRUCTURING THE FLUMINAN TERRITORY
}

\author{
Thiago Jeremias Baptista ${ }^{1}$ \\ ${ }^{1}$ Secretaria de Estado de Educação (SEEDUC), Rio de Janeiro, RJ, Brasil \\ Correspondência para: Thiago Jeremias Baptista (thiagobapt@hotmail.com) \\ doi: 10.12957/geouerj.2017.32067 \\ Recebido em: 1 nov. 2017 | Aceito em: 12 dez. 2017
}

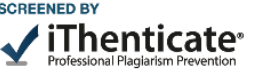

\section{RESUMO}

O aumento na circulação dos fluxos de investimentos externos diretos (IED) nas últimas décadas implicou um salto, de aproximadamente, US\$650 bilhões, ao final da década de 1990, para US\$1,76 trilhão, em 2015. Nesse contexto, o Brasil se destacou pelo aumento do influxo de investimentos externos diretos em seu território. $\mathrm{Na}$ esteira da ampliação do influxo de IED no país, um fenômeno recente vem se revelando, e consiste na ampliação dos investimentos chineses no território nacional. Esse processo exige uma reflexão acerca da internacionalização do capital, da desregulação dos fluxos financeiros e da abertura econômica do país orientada pelo neoliberalismo. Neste sentido, o artigo se volta a identificar o volume de investimentos chineses no território nacional entre 2007-2016, assim como a evidenciar a inserção do território fluminense nesse processo, haja vista que no período compreendido pelos anos 2010-2016, o estado do Rio de Janeiro recebeu, aproximadamente, US $\$ 21,9$ bilhões em investimentos oriundos daquele país asiático, o que resultou na implantação de dez projetos nos setores de energia, siderúrgico, ferroviário, infraestrutura, automotivo e de informática.

Palavras-chave: reestruturação; território fluminense, investimentos externos diretos, investimentos chineses, investimentos no Brasil.

\begin{abstract}
The rise in the circulation of direct external investment flows has overcome a leap in the last decade of U\$1,76 billion dollars at the end of the 90', to U\$1,76 trillion in 2015. In this context, Brazil has been in an important position due to the rise in the circulation of the direct external investment flows in its territory. On the heels of the enlargement of the direct external investment flows in the country, a recent phenomenon is being manifest, and it consists of the expansion of Chinese investments in the national territory. This process demands a reflection of the capital internationalisation, the deregulation of the financial flows, and the economic openness of the country, led by neoliberalism. This way, this article intends to identify the volume of Chinese investments in fluminense territory between 2007-2015, as well as emphasise the insertion of fluminense territory in this process, considering that in the period between 2010-2016, the state of Rio de Janeiro hás received approximately $U \$ 21,9$ billion dollars of investments coming from China, something that led to the implementation of 10 projects in energy, steel, railway, infrastructure, automotive and computational sectors.
\end{abstract}

Keywords: restructuring; fluminense territory, foreing direct investment, chinese investments; investments in Brazil

\section{INTRODUÇÃO}

A dimensão econômica do processo de globalização está relacionada a fenômenos que têm se intensificado nos últimos anos como, por exemplo, o aumento da concorrência e da integração dos 
mercados, assim como a expansão dos fluxos internacionais de bens, serviços e capitais (LACERDA, 2000). Na escala global, o aumento na circulação dos fluxos de investimentos externos diretos ${ }^{1}$ (IED), nas últimas décadas, contribuiu para um salto de, aproximadamente, US\$ 650 bilhões, ao final da década de 1990, para US\$1,76 trilhão, em 2015 .

Durante esse período, a República Popular da China se destacou, não somente como recipiendária de investimentos externos na Ásia Oriental, mas como um país que vem promovendo a internacionalização de seus investimentos. Segundo Cepal (2017), a República Popular da China, apresentou aumento sustentado de seus investimentos no exterior, alcançando a segunda posição enquanto origem de IED mundial (depois dos Estados Unidos). Neste sentido, faz-se necessário destacar que os fluxos de IED chineses saltaram de US\$ 830 milhões, em 1990, para US\$127 bilhões, em $2015^{2}$, alcançando US\$ 183,1 bilhões, em 2016 (CEPAL, 2017).

Nesse recorte temporal, o Brasil, em virtude da reforma administrativa realizada a partir da década de 1990, se caracterizou por um conjunto de mudanças em sua administração pública, consolidando o modelo gerencial orientado pelo neoliberalismo ${ }^{3}$, cujas bases se assentaram em pilares como a modernização, a privatização e a abertura ao capital estrangeiro (TENÓRIO e SARAIVA, 2006; ANDREWS, 2010; CASTRO, 2016; GIAMBAGI; 2016). Como resultado, a maior economia

\footnotetext{
1 "Por investimento direto entende-se o investimento realizado em país estrangeiro, onde a parte investidora (corporação, empresa) detém o controle do próprio investimento. O investimento direto surge tipicamente sob a forma de uma subsidiária de uma empresa estrangeira, ou quando esta assume o controle de uma firma já existente no país em questão" (SÖDERSTEN, 1979, p. 427).

${ }^{2}$ UNCTAD (Conferência das Nações Unidas sobre Comércio e Desenvolvimento - sigla em inglês)

<http://unctadstat.unctad.org/wds/TableViewer/tableView.aspx>. Acesso em: 10 jun 2017.

${ }^{3}$ Segundo Harvey (2012) o neoliberalismo é uma teoria das práticas político-econômicas em que o bem-estar humano é promovido através das liberdades e capacidades empreendedoras individuais no âmbito de uma estrutura institucional caracterizada pelo direito à propriedade privada, livre mercado e livre comércio, cabendo ao Estado preservar uma estrutura institucional apropriada a essas práticas. Neste sentido, o autor assinala que: "[...] o Estado tem de garantir, por exemplo, a qualidade e funções militares, de defesa, da polícia e legais requeridas para garantir direitos de propriedade individuais e para assegurar, se necessário pela força, o funcionamento apropriado dos mercados. Além disso, se não existem mercados (em áreas como a terra, a água, a instrução, o cuidado de saúde, a segurança social ou a poluição ambiental), estes devem se aventurar para além dessas tarefas. As intervenções do Estado nos mercados (uma vez criados) devem ser mantidas num nível mínimo, porque, de acordo com a teoria, o Estado possivelmente não possui informações suficientes para entender devidamente os sinais do mercado (preços) e porque poderosos grupos de interesse vão inevitavelmente distorcer e viciar as intervenções do Estado (particularmente nas democracias) em seu próprio benefício" (HARVEY, 2012, p. 12).
} 
sul-americana apresentou uma trajetória de ampliação como recipiendária de investimentos externos diretos, implicando o aumento da participação do IED no PIB nacional (ALVES, 2014).

A dimensão acerca do processo de aumento do influxo de capitais estrangeiros no Brasil, nos últimos anos, pode ser entendida quando notamos a sua passagem da condição de receptor de US\$ 392 milhões, em 1970, para ser recipiendário de US\$ 989 milhões, em 1990, alcançando US\$ 96,1 bilhões na recepção de IED, em 2011. Apesar da entrada de capitais estrangeiros ter se retraído recentemente, dada a recepção de US\$ 64,6 bilhões, em $2015^{4}$, o país ainda mantém posição relevante entre os receptores de investimentos externos na região.

Nesse primeiro quarto de décadas do século XXI, paralelo ao processo de influxo capitais estrangeiros no território nacional, tem ocorrido a ampliação de investimentos chineses no Brasil. Estabelecendo uma nova fase no âmbito das relações sino-brasileiras, a República Popular da China, não somente aumentou sua participação enquanto destino das exportações brasileiras ${ }^{5}$, como se destacou pelos seus investimentos em território nacional. Havendo assim, que se recordar do encontro entre os Presidentes Xi Jinping e Dilma Rousseff, em julho de 2014, quando mais de 50\% dos acordos assinados se concentraram nos setores comercial e de investimentos, bem como da recente visita ao país, do Primeiro-Ministro Chinês Li Keqiang, em maio de 2015; cuja ocasião resultou na assinatura de mais trinta atos e acordos bilaterais, atingindo, US $\$ 27$ bilhões ${ }^{6}$, destacando-se os setores de mineração, ciência e tecnologia e energia (CEBC, 2015).

A fim de preencher algumas lacunas sobre a origem do influxo de IED no país, o artigo em tela põe seu foco sobre a presença do capital sínico ${ }^{7}$ no território nacional, tendo como objetivo identificar o volume

\footnotetext{
${ }^{4}$ UNCTAD < http://unctad.org/en/Pages/Home.aspx $>$.

${ }^{5}$ A participação da República Popular da China como destino das exportações brasileiras saiu de 2\%, em 2000, para 6,2\%, em 2003, alcançando 15,2\%, em 2010, e saltando, para 19,2\%, em 2013, apresentando, entretanto, sensível recuo, para 18\%, em 2014. Com efeito, essa República Popular mantém posição relevante como parceiro comercial do Brasil desde 2010 , inserindo o país entre os seus 10 principais parceiros comerciais, haja vista que, Entre 2001 e 2014 o Brasil apresentou uma trajetória ascensional entre os principais parceiros comerciais da República Popular da China, saindo da $11^{\text {a }}$ posição para $8^{\text {a }}$ posição em 2013

${ }^{6}$ Disponível em: < http://cebc.org.br/sites/default/files/declaracao_imprensa___pm_li_keqiang.pdf $>$. Acesso em 22 nov. 2015

${ }^{7}$ Capital de origem chinesa.
} 
de investimentos chineses confirmados no Brasil entre 2007-2016 e evidenciar a inserção do território fluminense nesse processo. A condução da problematização deste estudo decorre da confirmação de investimentos chineses no estado do Rio de Janeiro, entre os anos 2010 e 2016.

Esse capital contribuiu para a implantação de atividades produtivas nos setores de energia, siderurgia, ferroviário, infraestrutura, informática e automotivo, em um território, que conforme aponta Oliveira (2012), tem se caracterizado, desde a década de 1990, pelas transformações estruturais em sua base econômica e em suas redes técnicas de suporte à implantação de novas atividades produtivas, assim como pelo movimento de inversão da concentração de recursos e investimentos. Neste sentido, procuramos compreender quais os motivos e/ou fatores conduzem a inserção do estado do Rio de Janeiro como recipiendário de investimentos chineses?

A fim de atender essas expectativas, alguns procedimentos metodológicos foram adotados para a realização deste estudo quali-quantitativo, compreendendo tanto i) o levanᄀtamento de referências sobre o tema em publicações acadêmicas e periódicos especializados, quanto ii) consultas ao sítio eletrônico da UNCTAD, para a realização do levantamento dos dados quantitativos sobre fluxos e estoques de IED no Brasil e sobre os fluxos e estoques de IED da República Popular da China no mundo. Assim como, iii) a sistematização dos dados referentes aos investimentos chineses confirmados no Brasil, entre 2007 e 2016, e confirmados no estado do Rio de Janeiro, entre 2010 e 2016, a partir das publicações do Centro Empresarial Brasil China (CEBC). Na busca pela compreensão do processo de reestruturação do território fluminense, realizamos iv) o levantamento da trajetória de crescimento do PIB estadual, entre os anos 1990-2014, bem como a participação de suas regiões de governo na composição econômica do estado do Rio de Janeiro, entre 2000-2012, a partir de dados da Fundação CEPERJ.

A estruturação do $\operatorname{artigo}^{8}$ em tela compreende três seções que sucedem essa introdução. Nas linhas correntes da primeira seção, evidenciamos o estado do Rio de Janeiro como nosso objeto de estudo e

\footnotetext{
${ }^{8}$ É um produto resultante dos estudos desenvolvidos durante o mestrado no Programa de Pós-Graduação em Geografia da UERJ, assim como da continuidade da pesquisa no doutoramento pelo Programa de Pós-Graduação em Geografia da PUC-
} 
resgatamos a trajetória econômica fluminense a fim de elencar a perda da centralidade política (1960) e a perda da centralidade econômica no decorrer do século XX. Consideramos o prisma do esvaziamento econômico e das perdas relativas, especialmente, para tratar o período compreendido entre os anos 1930-1980, para em seguida, abordarmos a reestruturação do território fluminense, após a década de 1990, evidenciando tanto a trajetória de crescimento do PIB do estado, quanto à reorganização da participação das regiões fluminenses na composição econômica estadual.

A segunda seção traz considerações sobre a passagem da República Popular da China da condição de recipiendário de investimentos externos a investidor internacional, identificando o volume de investimentos realizados pelo país asiático e a reorganização geográfica na distribuição dos seus investimentos no mundo nos últimos anos. A fim de identificar o volume de investimentos chineses no território nacional entre 2007-2016, apresentamos ao final da seção o influxo desses investimentos no Brasil e o número de projetos originados pelo capital sínico no país. Em seguida, a terceira seção trata a inserção do território fluminense no processo de internacionalização dos investimentos chineses, analisando os investimentos chineses confirmados no estado do Rio de Janeiro entre os anos 2010 e 2016, bem como a implantação de projetos de empresas chinesas que ocorreram neste período. Sendo esta seção, sucedida pelas considerações finais do artigo.

\section{O Território Fluminense: Trajetória Econômica e o Processo de Reestruturação}

\section{A trajetória econômica fluminense (1930-1980): a dupla perda de centralidade}

O atual recorte espacial compreendido pelo território fluminense foi caracterizado, durante o século XX, por uma dupla perda de centralidade ${ }^{9}$. Com a transferência do Distrito Federal para Brasília, em

\footnotetext{
Rio, ambos sob a orientação do Prof. Dr. Glaucio J. Marafon. Há que se destacar aqui, a contribuição da Prof.a Danielle Figueredo Elias na tradução do resumo para língua inglesa e revisão deste artigo.

${ }^{9}$ Por questões metodológicas que auxiliam na compreensão da atual configuração do estado do Rio de Janeiro, optamos em tratar, inicialmente, a perda da centralidade política da cidade do Rio de Janeiro decorrente da transferência do Distrito Federal para Brasília.
} 
1960, ocorre a perda da capitalidade e, por conseguinte, a perda da centralidade política do Rio de Janeiro.

Esse processo implicou a formação de duas Unidades Federativas (o estado da Guanabara e o estado do Rio de Janeiro), que quando fundidas, em 15 de março de 1975; originaram a atual configuração territorial do estado do Rio Janeiro. Em decorrência desse processo, uma nova centralidade política foi implantada na região Centro-Oeste, através da instalação de Brasília, no Planalto Central, como metrópole política do país (SANTOS e SILVEIRA, 2008).

A perda da centralidade econômica fluminense, entretanto, é decorrente de um processo longo, abrangendo algumas décadas do século XX. Assim aquela centralidade exercida pelo espaço fluminense que, até o início daquele século, esteve atrelada à proeminência econômica, processualmente obtida nos períodos colonial, imperial e republicano do Brasil, dado o acúmulo de funções (comercial, portuária, militar, industrial e da administração pública), foi perdida com o intenso desenvolvimento industrial no estado de São Paulo e a afirmação da cidade de São Paulo como a metrópole econômica do país (SANTOS e SILVEIRA, 2008).

Acerca do processo de perda de centralidade econômica fluminense, os trabalhos de Melo (2001) e Silva (2012) elencam o período de 1930-1980, respectivamente, sob o prisma do esvaziamento econômico e das perdas relativas, denotando uma conjuntura econômica involutiva que além de abarcar a perda de centralidade mencionada, evidenciam, respectivamente, tanto o processo de perda de participação fluminense na produção industrial do país, quanto à redução do Rio de Janeiro no PIB nacional.

Melo (2001) e Melo e Araújo (2014) evidenciam que, entre os anos 1930-1980, o estado do Rio de Janeiro assistiu um esvaziamento econômico em decorrência da trajetória de diminuição de sua participação em percentuais na produção industrial brasileira. Todavia os autores apontam que, apesar de ser o berço da industrialização do país, a indústria fluminense assistiu, desde a década de 1930, a um inexorável processo de esvaziamento, perdendo posição para a indústria paulista. 
Como resultado, naquela década, a participação do Rio de Janeiro somada com a do Distrito Federal, correspondia a menos da metade da participação do estado de São Paulo na produção industrial do país, sendo mantida a trajetória de redução da participação fluminense na produção industrial nacional ao longo de praticamente toda segunda metade do século XX. Portanto, se por um lado a participação fluminense na produção industrial, entre 1907 e 2000, apresentou retração de, aproximadamente, $31 \%$, dada a queda de $40 \%$, em 1907, para 8,6\%, em 2000. Por outro lado, o estado de São Paulo apresentou uma trajetória ascendente, destacadamente, entre 1907 e 1975, com uma participação na produção industrial nacional que saltou de $16,5 \%$, naquele ano, para quase $60 \%$, em meados da década de 1970 (Gráfico 1).

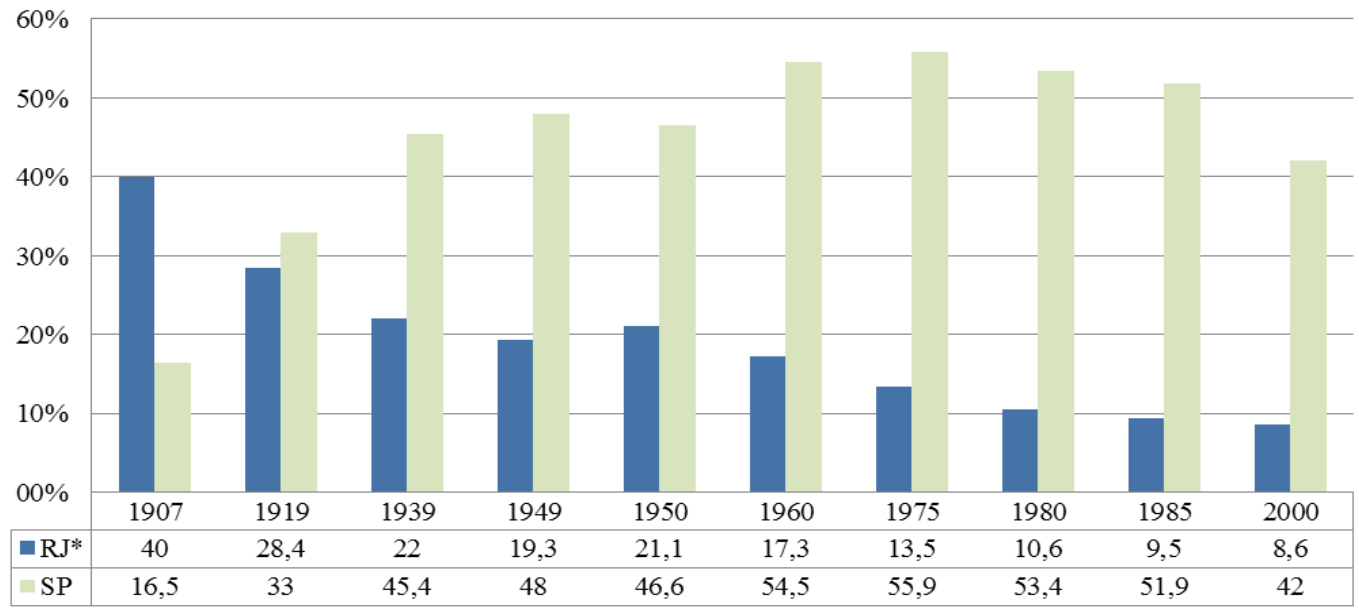

Gráfico 1. Rio de Janeiro e São Paulo: participação na produção industrial do Brasil entre 1907-2000

*Soma da cidade do Rio de Janeiro com o estado do Rio de Janeiro entre 1907-1975.

Fonte: MELO, 2001 e ARAÚJO e MELO, 2014 - Gráfico elaborado pelo autor.

A partir dessas considerações, pode-se compreender que, a trajetória econômica fluminense ao longo do século XX, destacadamente entre 1930-1980, foi marcada pela sua perda de centralidade econômica, em decorrência tanto da redução de sua participação na produção industrial nacional, quanto pela retração da contribuição fluminense no PIB nacional, implicando o ingresso do território fluminense numa trajetória que foi denominada de "esvaziamento econômico", e que mais 
recentemente, foi compreendida enquanto "perdas relativas" de participação fluminense na economia nacional (MELO, 2001; SILVA, 2012; ARAÚJO e MELO, 2014).

No entanto, ainda que marcado por uma conjuntura econômica involutiva, decorrente do negativo desempenho da economia nacional nos anos 1980, o estado do Rio de Janeiro, teve que aguardar a década de 1990 para assistir um conjunto de mudanças atreladas à implantação de novas atividades produtivas, a realização de novos investimentos em infraestrutura e as alterações nas bases de suas economias regionais, o que desencadearia seu processo de reestruturação. Estas mudanças são discutidas nas linhas subsequentes quando se volta atenção à compreensão sobre o processo de reestruturação do território fluminense e a inserção dos investimentos chineses no estado no início do século XXI.

\section{A trajetória econômica fluminense (pós-1990): o processo de reestruturação e o influxo de investimentos chineses}

A atual configuração territorial do estado do Rio de Janeiro (Figura 1), com extensão de 43,7 mil km², permite que esta Unidade Federativa (UF) estabeleça divisas com outros três estados da região Sudeste do Brasil, apresentando, uma organização político-administrativa, hodiernamente, formada por 8 regiões de governo e malha municipal constituída por 92 municípios. O estado Rio do Janeiro não está apenas próximo do Espírito Santo, Minas Gerais e São Paulo, sendo juntamente com estas UF, responsável por, aproximadamente, $55 \%$ do PIB nacional. 
A Região Metropolitana do Rio de Janeiro (RMRJ) e o Interior Fluminense

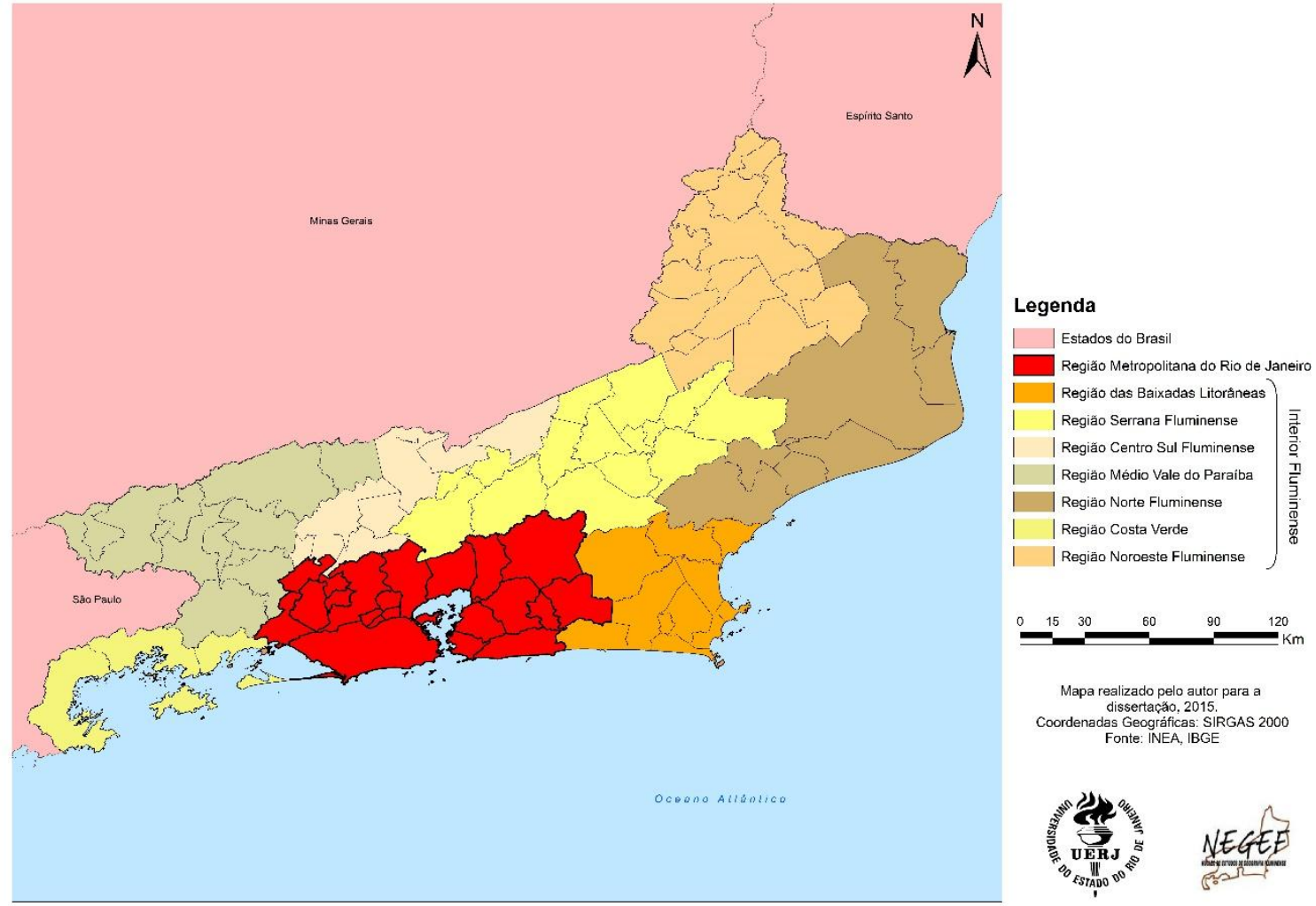

Figura 1. Estado do Rio de Janeiro: a RMRJ e o interior fluminense.

A Região Metropoitana do rio de Janeiro ( RMRJ) E O Interior Fluminense.

Fonte: O Autor, 2015.

Tamanha concentração na composição do PIB do país evidencia tanto a característica assimétrica do desenvolvimento capitalista brasileiro (SILVA, 2012), quanto justifica a manutenção de uma agenda de pesquisa acerca do território fluminense, sobretudo, pela sua importância no âmbito econômico e produtivo nacional. Segundo Oliveira ${ }^{10}$ (2012, p. 131), "o território fluminense necessita ser estudado em sua totalidade, como espaço social que passa por um conjunto de mudanças nas condições gerais de produção", destacadamente, por que:

a organização do território fluminense como um todo, passou nas últimas duas décadas, por transformações estruturais em sua base econômica e nas redes técnicas de suporte às novas atividades produtivas, iniciando um movimento de inversão da concentração de recursos, população e investimentos que caracterizaram as duas cidades do núcleo metropolitano, ou seja, Rio de Janeiro e Niterói.

Essas novas atividades, a princípio, foram resultantes de ações empresariais que atuam no mercado internacional, cujas decisões ocorrem nos principais centros econômicos do capitalismo contemporâneo. A partir desses centros é que são decididos os usos dos territórios, apropriando-

\footnotetext{
${ }^{10}$ Com base em Lencioni (2007).
} 
se dos recursos existentes em cada lugar por setores econômicos globalizados, cujos objetivos são pura e simplesmente a exploração dos recursos locais e a acumulação de capitais (OLIVEIRA, 2012, p. 132).

Convergimos com Oliveira (2012) quando o autor aponta que, o estado do Rio de Janeiro, enquanto "um território em mudanças", tem suas principais transformações territoriais relacionadas aos processos de transformações das bases econômicas, iniciados nos primeiros anos da década de 1990 , destacadamente, quando assinala que:

as mudanças nas bases técnicas no interior do estado, sobretudo, no Norte Fluminense, cujas bases econômicas eram atividades agroindustriais sucroalcooleiras e, hoje, predominam a indústria do petróleo e gás, por meio das atividades extrativistas e logísticas. No outro extremo no sul do estado, onde havia uma base isolada do setor siderúrgico, liderada pela Companhia Siderúrgica Nacional (CSN), instala-se um complexo polo metal-mecânico e siderúrgico ampliado pelas indústrias automobilísticas e pelas atividades portuárias da região (OLIVEIRA 2012, p. 132-133)

Essas mudanças, segundo o autor supracitado, só ganham visibilidade quando atingem o espaço metropolitano, influindo na reversão do quadro de estagnação que perdurou até a década de 1980 e início dos anos 1990. Especialmente com a instalação de novos fixos nessa porção do território e o (re)acionamento de setores produtivos localizados na Região Metropolitana do Rio de Janeiro (RMRJ), que se encontravam estagnados como, por exemplo, a indústria naval.

Na perspectiva de Silva (2012), essas mudanças contribuíram para que o território fluminense chegasse ao século XXI, com seu interior, constituído por um parque industrial dotado de novas plantas industriais, porém, pouco articulado, dado o estabelecimento, de dois padrões de especialização: o da produção petrolífera do Norte Fluminense e o da produção manufatureira no Sul Fluminense. Cabendo a RMRJ, apesar de sua densidade econômica e demográfica, assistir um padrão de desenvolvimento assentado na terciarização e na desindustrialização, bem como um processo de mudança na sua contribuição percentual na economia fluminense.

Diante do exposto acerca das mudanças que ocorrem no território fluminense, após a década de 1990, consideramos sua reestruturação sob o prisma econômico-produtivo. Considerando assim, a trajetória de influxo de investimentos no território fluminense e o crescimento econômico do estado do Rio de 
Janeiro, acompanhado da reorganização da participação de suas economias regionais na composição do PIB estadual.

A noção de reestruturação que nos orienta pode ser compreendida, conforme assinala Soja (1993), enquanto um processo resultante da modificação da estrutura de um espaço material, de maneira rápida ou lenta, ocorrendo em diferentes escalas, onde fatores econômicos, políticos e ideológicos, frequentemente combinados transmitem a noção de ruptura nas tendências seculares. Sendo esta noção também apreendida como um processo de mudança estrutural expressivo em direção a uma ordem e a uma configuração significativamente diferente na vida social, econômica e política (SANTOS, 2008;

SOUZA, 2013).

No caso do território fluminense, a superação da trajetória de estagnação ocorre pari passum ao processo de retomada de crescimento econômico do estado, apesar de não ter sido capaz de reverter a sua perda de importância na economia nacional - sendo esta mantida em, aproximadamente, 11\% -, ela se caracterizou por uma nova conjuntura econômico-produtiva. As principais características dessa nova conjuntura econômico-produtiva se constituem tanto pela trajetória influxos de investimentos e implantação de novas atividades produtivas no território, quanto pelo crescimento do seu PIB e reorganização dos percentuais de participação de suas economias regionais na economia do estado.

No que concerne ao crescimento econômico e a reorganização da participação das economias regionais, torna-se possível dimensionar a conjuntura de mudanças, quando o PIB fluminense saltou de $\mathrm{R} \$ 78,9$ milhões, em 1995, para $\mathrm{R} \$ 671,0$ milhões, em 2014; ampliando de modo pouco significativo seu percentual de participação na economia nacional entre 1995 e 2014, mantendo-se esta participação neste período entre $11 \%$ e $12 \%$, ou seja, pouco superior à contribuição apresentada na metade dos anos 1990 (Gráfico 3).

Além da conjuntura de mudanças pela qual passou o território fluminense poder ser evidenciada com o crescimento do PIB do estado do Rio de Janeiro, a partir da década de 1990, torna-se possível dimensionar esse processo com a reorganização das taxas de participação econômico-regional, em um período mais recente, destacadamente, entre os anos 2000 e 2014. Portanto, nota-se que neste período 
o crescimento do PIB estadual, saiu de $\mathrm{R} \$ 139,7$ milhões, em 2000 , para $\mathrm{R} \$ 671,0$ milhões, em 2014; ocorrendo o aumento da participação da porção interiorana do estado na economia fluminense. Como resultado, o interior fluminense elevou sua participação no PIB estadual, em 11,0\%, no referido período, passando sua contribuição no PIB estadual de 26\%, em 2000, para 37\% em 2014. No entanto, a Região Metropolitana do Rio de Janeiro assistiu tanto aos processos de desindustrialização e terciarização, assinalados por Silva (2012), quanto à diminuição de sua participação de $74 \%$, em 2000, para 63\%, em 2014 (Tabela 1), o que evidencia o processo de inversão da concentração econômico-produtiva e de recursos no território fluminense.

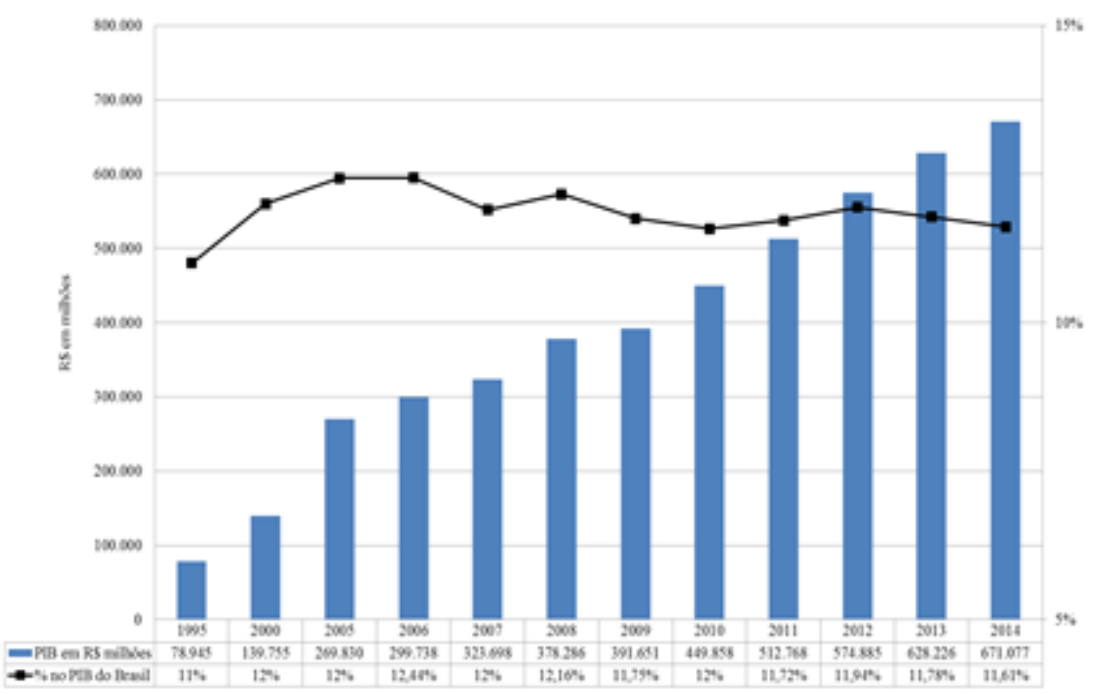

Gráfico 3. Estado do Rio de Janeiro: PIB e participação no PIB nacional entre 1995-2014

Fonte: FUNDAÇÃO CEPERJ. Disponível em: < http://www.ceperj.rj.gov.br/ceep/pib/pib.html>. Acesso em: 20 jul. 2017. - Gráfico elaborado pelo autor.

\begin{tabular}{rccc}
\hline Regiões de Governo & $\mathbf{2 0 0 0}$ & $\mathbf{2 0 1 4}$ \\
& $\mathbf{( \% )}$ & $\mathbf{( \% )}$ & Variação \% \\
\hline Metropolitana & $74 \%$ & $63 \%$ & $-11 \%$ \\
\hline Interior Fluminense & $26 \%$ & $37 \%$ & $11 \%$ \\
\hline Norte Fluminense & $7 \%$ & $16 \%$ & $9 \%$ \\
Médio Paraíba & $7 \%$ & $5 \%$ & $-2 \%$ \\
Serrana & $4 \%$ & $4 \%$ & $0 \%$ \\
Baixadas Litorâneas & $4 \%$ & $8 \%$ & $4 \%$ \\
Centro-Sul Fluminense & $1 \%$ & $1 \%$ & $0 \%$ \\
Noroeste Fluminense & $1 \%$ & $1 \%$ & $0 \%$ \\
Costa Verde & $1 \%$ & $2 \%$ & $1 \%$ \\
\hline
\end{tabular}

Tabela 1. Estado do Rio de Janeiro: PIB por regiões de governo (\%) (2000-2014) 
Fonte: FUNDAÇÃO CEPERJ. Disponível em: < http://www.ceperj.rj.gov.br/ceep/pib/pib.html>. Acesso em:

20 jul. 2017. - Tabela elaborada pelo autor como base na participação por atividade econômica e no valor adicionado bruto, segundo as Regiões de Governo e municípios 2000/2014.

Todavia como bem assinalam Terra et al (2012), em meio a essa conjuntura de mudanças, o supracitado estado, se destacou na carteira de investimentos industriais, logísticos e de serviços. No que concerne aos investimentos chineses confirmados no país, o estado do Rio de Janeiro, recebeu grande aporte desse capital. Com efeito, entre 2010-2016, o influxo de investimentos chineses no território fluminense compreendeu, aproximadamente, US\$21,9 bilhões, abrangendo assim, grande parte dos investimentos chineses confirmados no Brasil, entre 2007-2016, quando a soma desse capital compreendeu, aproximadamente, US\$ 46,1 bilhões (CEBC, 2017) (Gráfico 4).

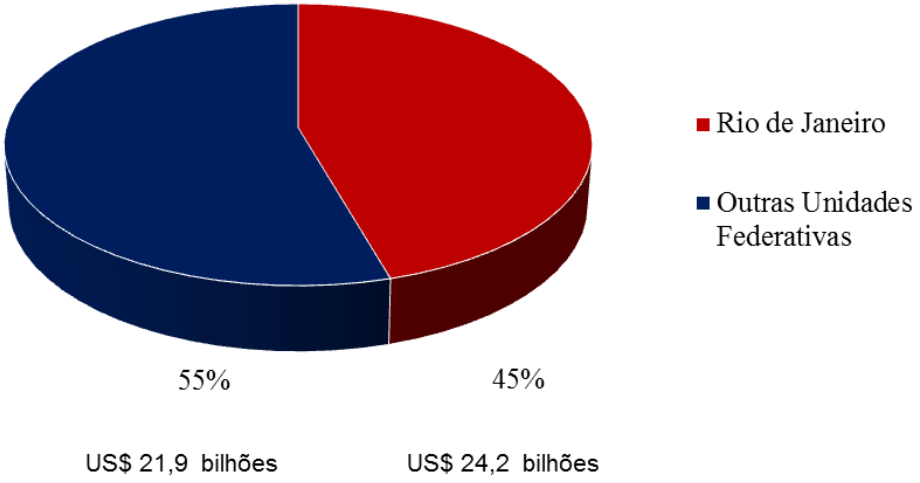

Gráfico 4. Investimentos chineses confirmados no estado do Rio de Janeiro Fonte: CEBC, 2017 - Gráfico elaborado pelo autor

\section{A reorganização geográfica dos investimentos chineses no mundo e a inserção do Brasil no processo de internacionalização dos IED chineses}

No final dos anos 1970, a República Popular da China ${ }^{11}$ assistiu à abertura econômica aos investimentos estrangeiros e as reformas realizadas pelo Governo Deng Xiaoping (1978-1992). Como

\footnotetext{
${ }^{11}$ Com uma projeção histórico-econômica muito densa, reconhecemos conforme assinala Kissinger (2011, p. 21), que "qualquer tentativa de compreender [...] o papel mundial da China no século XXI deve começar - mesmo ao preço de uma possível simplificação excessiva - por uma apreciação básica do contexto tradicional”. Neste sentido, sinalizamos que este país localizado na Ásia Oriental, tem um contexto tradicional que remonta o período de Estados Combatentes e à unificação
} 
resultado, o país asiático ascendeu, ao longo de seu processo de desenvolvimento econômico, de recipiendário de investimentos estrangeiros à condição de investidor internacional.

O influxo de investimentos externos na República Popular da China se manteve crescente, ao longo do último quarto de décadas do século XX e o início do século XXI, ocorrendo um salto de, aproximadamente, US\$ 57 milhões, em 1980, para US\$1,9 bilhão, em 1985, assim como considerável trajetória de ampliação dos US\$ 37,5 bilhões, em 1995, ao atingir US $\$ 135,6$ bilhões, em 2015 (Gráfico 5). Sendo possível notar que, o período de maior influxo de investimentos no território chinês compreende o recorte temporal entre os anos1990 e as primeiras décadas do século corrente.

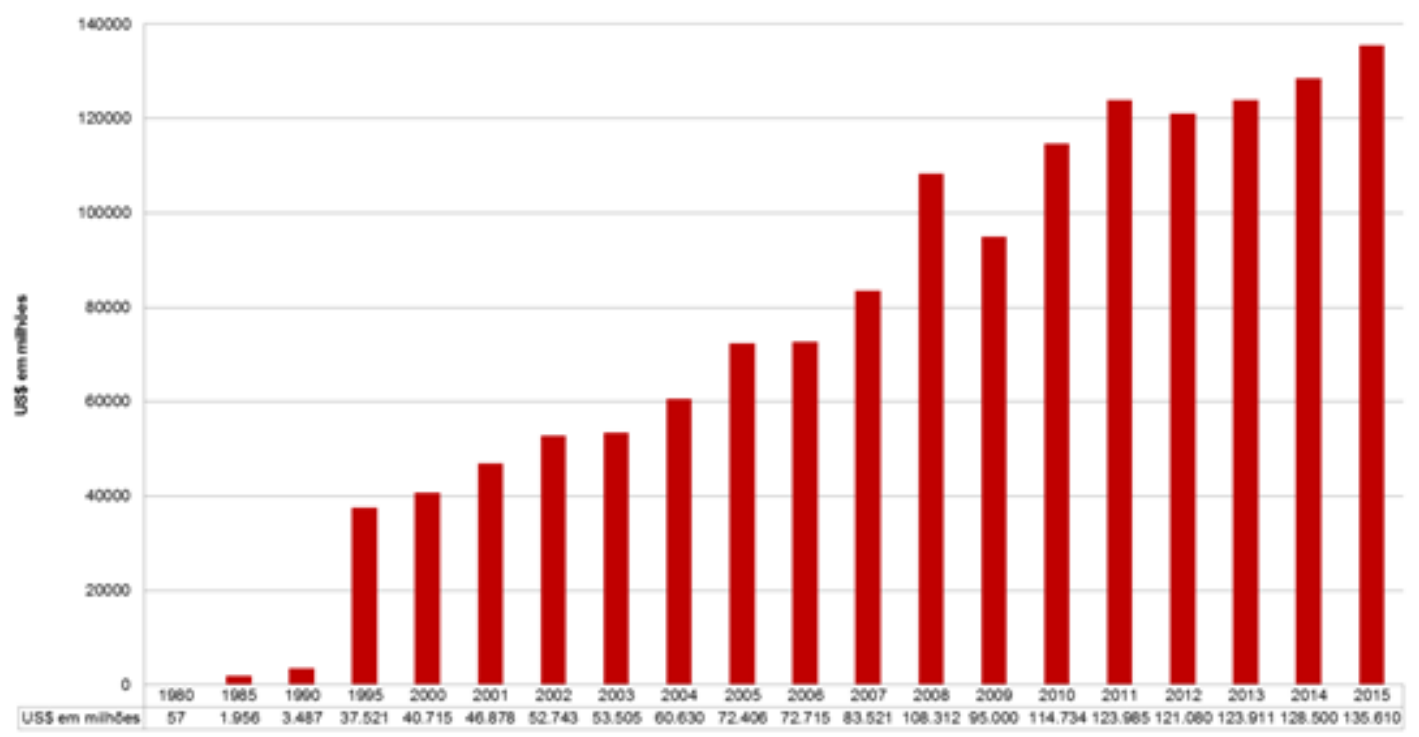

Gráfico 5. República Popular da China: influxo de IED - 1980-2015

Fonte: <http://unctadstat.unctad.org/wds/TableViewer/tableView.aspx >. Acesso em: 10 jun 2017. Gráfico elaborado pelo autor.

No que concerne à internacionalização dos investimentos chineses, pode-se compreender que embora as primeiras concessões para efetuar investimentos no exterior remontem a passagem entre os anos 1979-1980, foi somente a partir da década de 1990, que aquele país ampliou sua participação no fluxo e no estoque de IED no mundo (BUCKLEY et al, 2010; OLIVEIRA, A. 2012, CEBC, 2013; ALVES, 2014). Como resultado, a República Popular da China atingiu US\$127,5 bilhões, em fluxos de investimentos no exterior, em 2015, alcançando US\$ 1,0 trilhão, em seus estoques de IED no mesmo ano (Gráfico 6).

territorial em 221 a.C, que conformou o Império Chinês. Nesta seção, abordaremos a China que após se reunificar no início do século XX - com a instauração da República (1912) - e passar por um processo revolucionário em 1949 - que tirou o país asiático do século da humilhação e o conduziu à atual República Popular da China. 


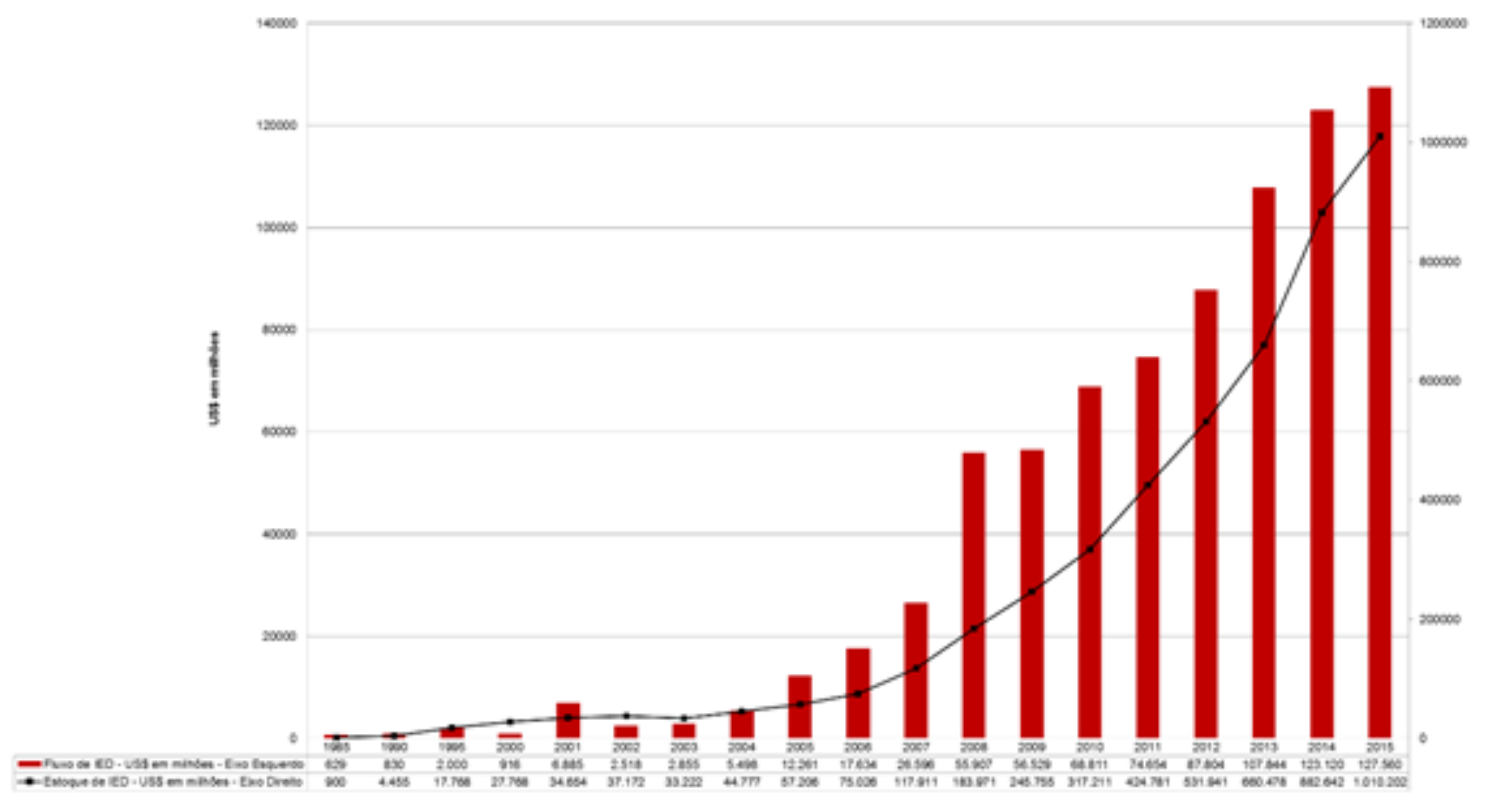

Gráfico 6. República Popular da China: fluxo e estoque de IED no exterior - 1980-2015

Fonte: <http://unctadstat.unctad.org/wds/TableViewer/tableView.aspx>. Acesso em: 10 jun 2017. Gráfico elaborado pelo autor.

O desempenho alcançado como investidor internacional pela República Popular da China remonta uma trajetória gradual de expansão de seus investimentos no exterior ${ }^{12}$, dotando-a de capacidades políticoeconômicas de investir em diferentes regiões do mundo com assertividade e pragmatismo. Com efeito, o país asiático expandiu a atuação de suas empresas estatais e investiu em diferentes regiões do espaço mundial.

A República Popular da China manteve, inicialmente, a maior parte dos seus investimentos externos em países desenvolvidos, entretanto, mais recentemente, a reorganização geográfica na distribuição espacial de seus investimentos no exterior conduziu os países em desenvolvimento à condição de maiores receptores de IED chineses (IPEA, 2011). Assim, os fluxos e estoques de IED chineses, em 2012, se concentravam na Ásia e na América Latina e Caribe, sendo estas regiões seguidas, no que concerne aos fluxos, pela Europa, América do Norte, economias em transição, outros países desenvolvidos e África. No que tange aos estoques, Ásia e América Latina e Caribe são sucedidas pela

\footnotetext{
${ }^{12}$ Acerca desse processo ver Buckley et al (2010), Oliveira, A. (2012), Cebc (2013) e Alves (2014).
} 
Europa, América do Norte, outros países desenvolvidos, África e economias em transição (Gráfico $\left.7^{13}\right)$

A) RPC: fluxos de IED por regiões em 2012 B) estoques de IED por regiões 2012
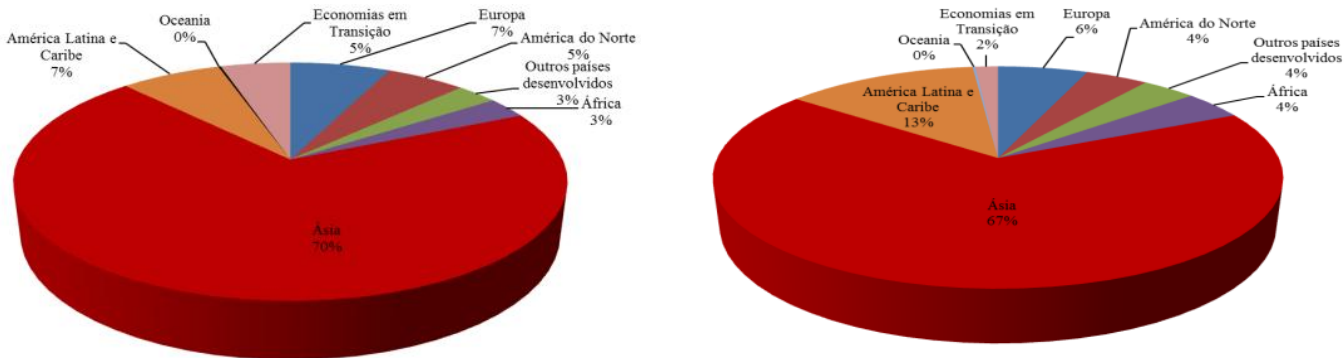

Gráfico 7. Tipos de produtores rurais dos municípios estudados no EDR de Presidente Prudente/SP.

Fonte: UNCTAD. Disponível em:

<http://unctad.org/Sections/dite_fdistat/docs/webdiaeia2014d3_CHN.pdf>. Acesso em 20 jul. 2017 -

Gráfico elaborado pelo autor.

No que concerne às relações sino-brasileiras, conforme assinalado, a República Popular da China, além de principal parceiro comercial do Brasil, vem se destacando no relacionamento bilateral com este país sul-americano, como um novo investidor internacional. Com efeito, durante o período compreendido entre os anos 2007 e 2016, é possível identificar que US\$ 46,1 bilhões em IED chineses foram confirmados no território nacional (Gráfico 8).

Diante do exposto, percebe-se que embora presente entre 2007-2009, o influxo de investimentos chineses confirmados no país foi baixo, compreendendo quando somados US\$549 milhões. Entretanto, a partir de 2010, o ingresso desses investimentos foi consideravelmente ampliado no território nacional, dada a confirmação de US\$13,0 bilhões, sendo sucedido, nos anos subsequentes, por novos investimentos, que apesar de menores em relação ao ano de 2010, como: US\$ 8,0 bilhões, em 2011, US\$ 3,4 bilhões, em 2012, US\$ 3,4 bilhões, em 2013, US\$1,7 bilhões, em 2014, US\$ 7,4 bilhões, em 2015, e US\$ 8,3 bilhões, em 2016; compreendem volumes de investimentos confirmados que não se mostraram inferiores ao período de 2007-2009.

13 Terminologias da UNCTAD. 


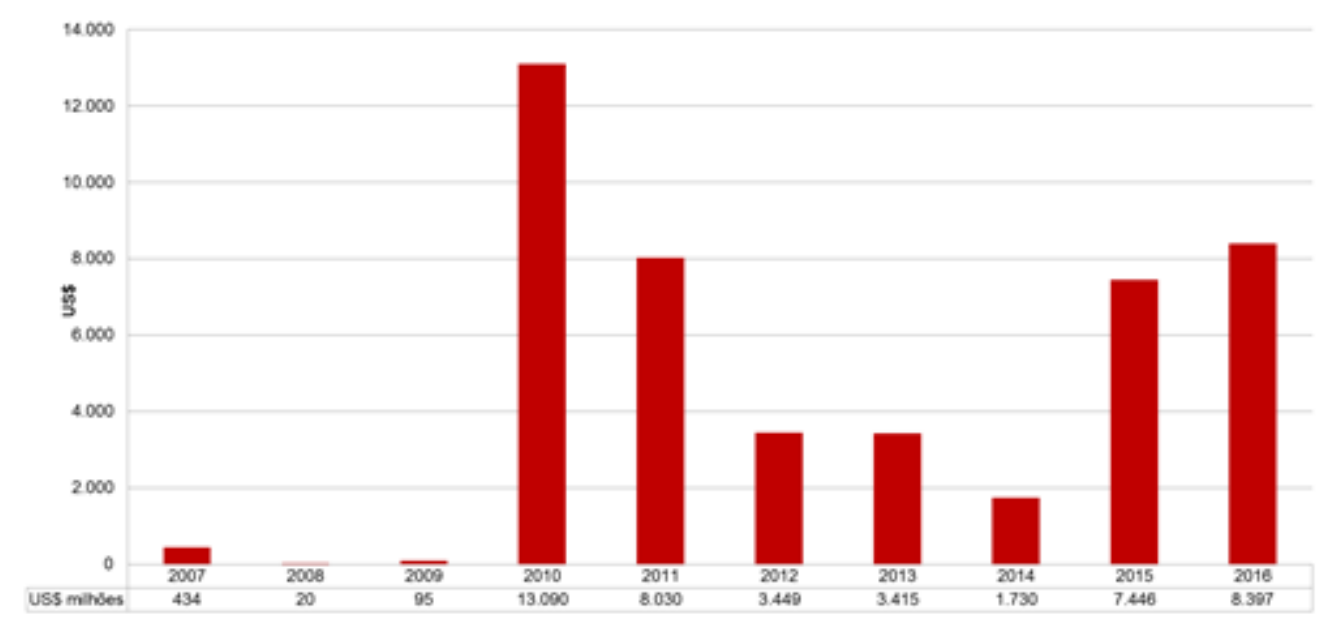

Gráfico 8. Investimentos externos diretos chineses confirmados no Brasil - 2007-2016

Fonte: Fonte: CEBC, 2017 - Gráfico elaborado pelo autor.

Portanto, se por um lado, entre 2010-2014 houve redução do aporte de investimentos chineses no Brasil, por outro lado, entre 2014-2016, houve a retomada desses investimentos no país. O volume de capital chinês investido no país ao longo dos anos 2007-2016 equivaleu à confirmação de oitenta e oito projetos (Gráfico 9).

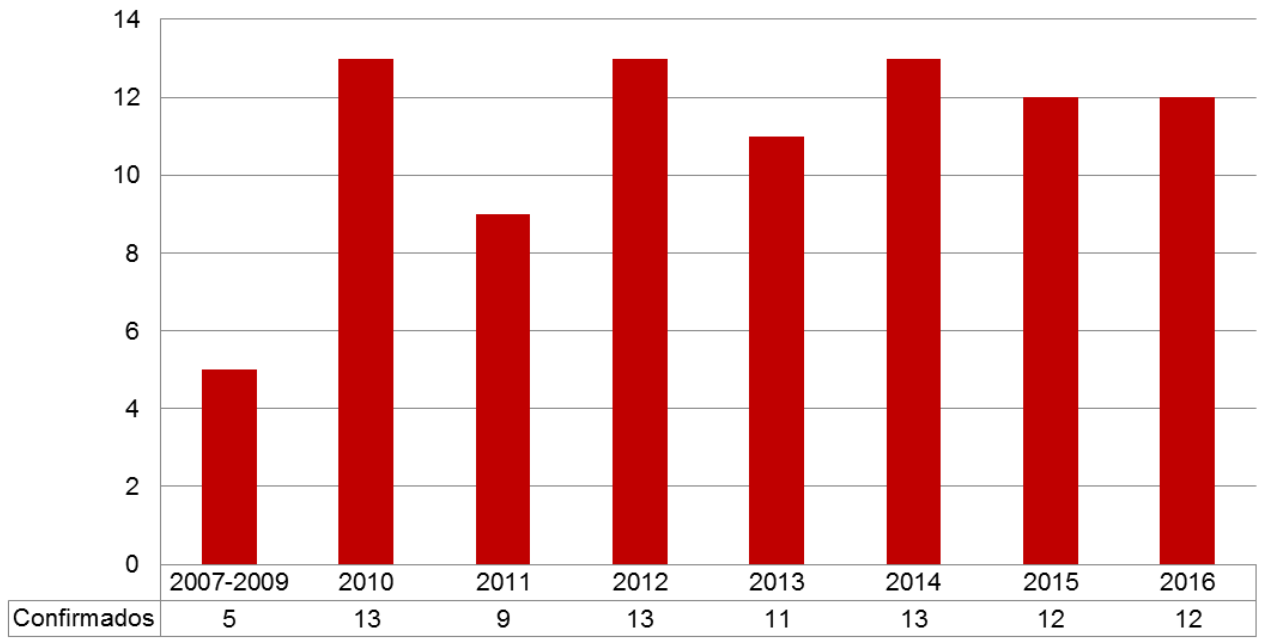

Gráfico 9. Projetos de investimentos chineses no Brasil - 2007-2016

Fonte: CEBC, 2016 - Gráfico elaborado pelo autor.

O número de projetos e o volume de capitais investidos nos setores de energia e agronegócio foram representativos. No entanto, outros setores como o de siderurgia, máquinas e equipamentos, automobilístico, aviação, financeiro, e mais recentemente, os setores de informática e de infraestrutura 
tem diversificado as atividades receptoras de investimentos chineses no Brasil (CEBC, 2015; 2016; 2017).

Nota-se no caso brasileiro, que como desdobramento da influência da teoria neoliberal na reforma administrativa do país, ocorre tanto um processo de reestruturação do Estado através da abertura econômica, das privatizações e da redução do intervencionismo, quanto à participação mais recente do capital sínico no processo de "desnacionalização profunda”, apontado por Miranda e Tavares (1999), e de "transnacionalização do território", assinalado por Santos (2012). Diante desses processos, cabenos na próxima seção, evidenciar a inserção do estado do Rio de Janeiro como recipiendário desse influxo de investimentos chineses no País.

\section{A inserção do estado do Rio de Janeiro no processo de internacionalização dos investimentos chineses}

Apesar de apresentarem contribuições acerca da retomada do crescimento econômico do estado do Rio de Janeiro, evidenciarem a reestruturação produtiva do território nas últimas duas décadas e avaliarem a trajetória econômica fluminense ao longo da passagem do século XX para o século XXI, os estudos elencados neste artigo, não enfatizam o influxo dos investimentos chineses no território fluminense.

No sentido de preencher essa lacuna, identificamos a partir das publicações do CEBC, que no período compreendido pelos anos 2007-2016, os investimentos chineses confirmados no Brasil compreenderam, aproximadamente, US\$ 46,1 bilhões. No território nacional, a região Sudeste se destaca como o centro de gravidade dos investimentos chineses, concentrando grande parte dos empreendimentos chineses realizados no país (CEBC, 2017).

Entre as Unidades Federativas, não somente na escala regional, mas também na escala nacional, os estados de São Paulo e Rio de Janeiro se destacam como recipiendários desses investimentos. O estado do Rio de Janeiro, entre 2010 e 2016, foi inserido no processo de internacionalização dos 
investimentos chineses, dado o influxo de aproximadamente US\$21,9 bilhões. Esse volume de capital representou, aproximadamente, 45,5\%, do montante dos investimentos chineses confirmados no país, correspondendo assim, a implantação de dez projetos no território fluminense.

Os projetos que materializam os investimentos chineses no território fluminense abrangem os setores de energia, siderurgia, infraestrutura, ferroviário, informática e automotivo (Tabela 2). Sendo possível notar uma trajetória de continuidade dos investimentos chineses no estado, apesar da exceção nos anos 2012 e 2014, a década corrente tem sido marcada pela entrada de IED chineses no estado.

\begin{tabular}{|c|c|c|c|c|c|c|c|}
\hline Projeto & Ano & $\begin{array}{c}\text { Empresa } \\
\text { Origem } \\
\end{array}$ & Valor em US\$ & $\begin{array}{l}\text { Modo de } \\
\text { Entrada } \\
\end{array}$ & Setor & $\begin{array}{l}\text { Estrutura de } \\
\text { Propriedade } \\
\end{array}$ & $\begin{array}{c}\text { Determinante do } \\
\text { Investimento } \\
\end{array}$ \\
\hline 1 & 2010 & $\begin{array}{l}\text { Sinopec } \\
\text { Repsol } \\
\text { Brasil* }\end{array}$ & 7.109 .000 .000 & $\begin{array}{l}\text { Fusões \& } \\
\text { Aquisições } \\
\text { (parcial) }\end{array}$ & $\begin{array}{c}\text { Energia } \\
\text { (petróleo e gás) }\end{array}$ & Central SOE & Busca de Recursos \\
\hline 2 & 2010 & $\begin{array}{c}\text { Sinochem } \\
\text { Statoil ASA** }\end{array}$ & 3.070 .000 .000 & $\begin{array}{l}\text { Fusões \& } \\
\text { Aquisições } \\
\text { (parcial) }\end{array}$ & $\begin{array}{c}\text { Energia } \\
\text { (petróleo e gás) }\end{array}$ & Central SOE & Busca de Recursos \\
\hline 3 & 2010 & $\begin{array}{l}\text { CR Zong- } \\
\text { shen*** }\end{array}$ & 20.000 .000 & Greenfield & Automotivo & Privada & Busca de Mercado \\
\hline 4 & 2010 & $\begin{array}{c}\text { Wuhan } \\
\text { Iron/Stell } \\
\text { Group Co. } \\
\text { (Wisco)**** }\end{array}$ & 3.500 .000 .000 & Joint Venture & Siderurgia & Central SOE & Busca de Recursos \\
\hline 5 & 2011 & $\begin{array}{c}\text { China } \\
\text { Northern } \\
\text { Railway } \\
* * * * *\end{array}$ & 200.000 .000 & $\begin{array}{l}\text { Fusões \& } \\
\text { Aquisições } \\
\text { (completa) }\end{array}$ & Ferroviário & SOE & Busca de Mercado \\
\hline 6 & 2011 & $\begin{array}{l}\text { Sinopec } \\
* * * * * *\end{array}$ & 3.500 .000 .000 & $\begin{array}{l}\text { Fusões \& } \\
\text { Aquisições } \\
\text { (parcial) }\end{array}$ & $\begin{array}{c}\text { Energia } \\
\text { (Petróleo e Gás) }\end{array}$ & Central SOE & Busca de Recursos \\
\hline 7 & 2013 & $\begin{array}{l}\text { CNPC e } \\
\text { CNOOC } \\
* * * * * * *\end{array}$ & 1.500 .000 .000 & $\begin{array}{l}\text { Fusões \& } \\
\text { Aquisições } \\
\text { (parcial) }\end{array}$ & $\begin{array}{c}\text { Energia } \\
\text { (Petróleo e Gás) }\end{array}$ & Central SOE & Busca de Recursos \\
\hline 8 & 2015 & Qihoo & 21.000 .000 & $\begin{array}{l}\text { Fusões \& } \\
\text { Aquisições }\end{array}$ & Informática & Privada & Busca de Mercado \\
\hline 9 & 2015 & $\begin{array}{l}\text { State Grid } \\
* * * * * * * *\end{array}$ & 2.905 .808 .000 & $\begin{array}{l}\text { Fusões \& } \\
\text { Aquisições } \\
\text { (parcial) }\end{array}$ & Energia & Central SOE & Busca de Mercado \\
\hline 10 & 2016 & $\begin{array}{c}\text { China } \\
\text { Communica- } \\
\text { tions } \\
\text { Construction } \\
\text { Company } \\
* * * * * * * * *\end{array}$ & 100.000 .000 & Joint Venture & Infraestrutura & Central SOE & Busca de Mercado \\
\hline
\end{tabular}


* "Compra de 40\% das operações brasileiras da empresa espanhola REPSOL" (OLIVEIRA, A. 2012, p. 209).

** "Aquisição de 40\% da exploração do Campo de petróleo offshore Peregrino (Bacia de Campos)" (OLIVEIRA, A. 2012, p.209).

*** "Instalação de fábrica utilizando a marca KASINSKI" (OLIVEIRA, 2012, p. 210).

**** "Instalação de siderúrgica, com 70\% de participação da Wisco na joint venture (Porto do Açú - São João da Barra)" (OLIVEIRA, A. 2012, p. 210).

***** "Fabricação de 34 trens para o Governo do Estado do Rio de Janeiro. O valor será investido na aquisição de maquinário e modernização de planta já existente. A previsão é alcançar 2.500 trabalhadores" (OLIVEIRA A, 2012, p. 211).

****** "30\% dos ativos da Galp no Brasil" (OLIVEIRA, A. 2012, p. 2011).

******* “As empresas chinesas CNPC e CNOOC arremataram, em conjunto com a anglo-holandesa Shell, a francesa Total e a brasileira Petrobras, a concessão para exploração de petróleo e gás no Campo de Libra, no pré-sal da Bacia de Campos” (CEBC, 2014, p. 16).

*********A "A State Grid Brazil Holding venceu o leilão realizado pela Agência Nacional de Energia Elétrica (ANEEL) para a construção da segunda linha de transmissão de Belo Monte. A linha reforçará o escoamento da produção da energia produzida na hidrelétrica até o Sudeste. [...] 0 investimento previsto é de $\mathrm{R} \$ 7$ bilhões e as obras serão realizadas em cinco estados: Pará, Tocantins, Goiás, Minas Gerais e Rio de Janeiro" (CEBC, 2016, p. 28). Entretanto, foram confirmados US\$2.095.000,00 em investimentos cujos projetos contemplaram os referidos estados (CEBC, 2016, p. 30).

********* “A empresa China Communications Construction Company (CCCC) acertou a aquisição de 80\% do capital da construtora brasileira Concremat Engenharia no valor de $\mathrm{R} \$ 350$ milhões. 0 grupo chinês tem interesses em projetos de infraestrutura, equipamentos pesados e serviços de dragagem no Brasil, onde pretende investir US \$1 bilhão no médio prazo. A Concremat confirmou ter assinado um acordo preliminar, com os termos e condições a serem definidos posteriormente" (CEBC, 2017, p. 24).

Tabela 2. Investimentos chineses confirmados no território fluminense: 2010-2016

Fonte: OLIVEIRA, A. 2012 e CEBC 2013; 2014; 2015; 2016; 2017 - Tabela elaborada pelo autor.

Outro aspecto que pode ser observado consiste na estrutura de propriedade das empresas. Entre os dez projetos chineses realizados no estado do Rio de Janeiro, apenas dois projetos, foram realizados por empresas privadas - um no setor automotivo e outro no setor de informática. Enquanto os investimentos realizados por empresas estatais chinesas correspondem a oito projetos (Gráfico 10). Entre os oito projetos realizados por estatais chinesas, cinco estão relacionados ao setor de energia, destacadamente, no segmento óleo e gás - que abrange quatro desses projetos. Enquanto os outros três projetos contemplam os setores siderúrgico, ferroviário e de infraestrutura.

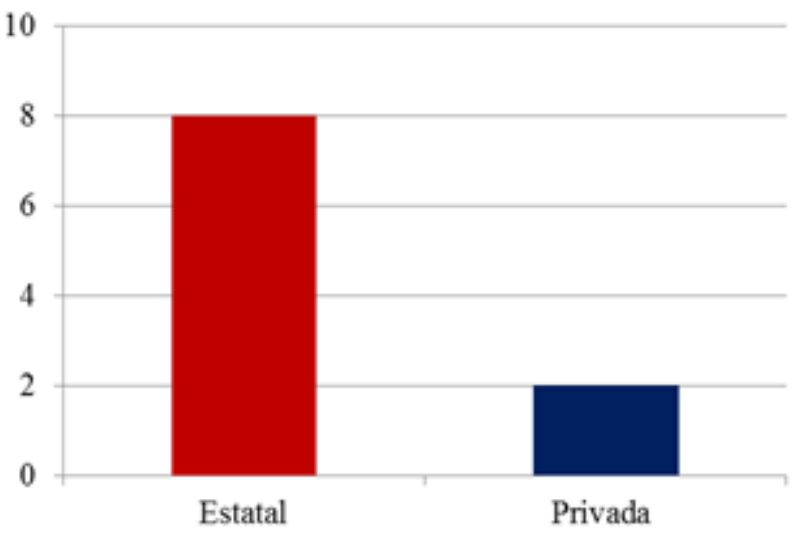

Gráfico 10. Número de projetos chineses no território fluminense por estrutura de propriedade das empresas 2010-2016

Fonte: O Autor 2017. 
Com efeito, o setor de energia não corresponde apenas ao maior número de projetos, mas abrange 0 maior volume de capital investido pelas estatais chinesas no estado do Rio de Janeiro, compreendendo, aproximadamente, a US\$ 18,0 bilhões, ou seja, 82,4\% dos investimentos realizados no território fluminense, entre 2010-2016. Por outro lado, os investimentos nos setores de informática, automotivo, infraestrutura, ferroviário e siderúrgico, compreendem, tanto os menores volumes em investimentos, quanto apenas um projeto em cada um desses setores, assim como os menores percentuais, conforme evidencia o Gráfico 11.

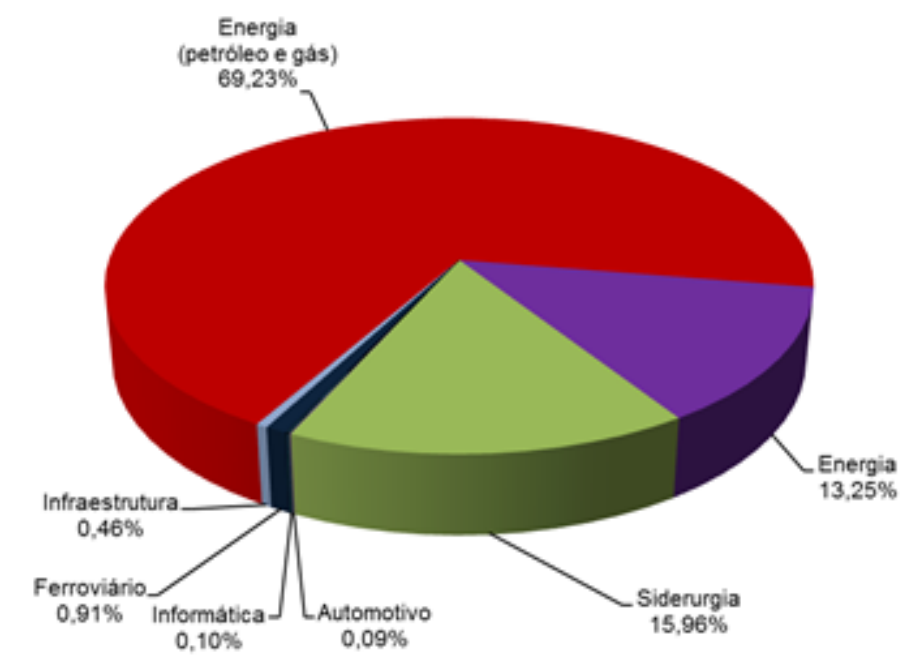

Gráfico 11. Investimentos chineses no estado do Rio de Janeiro: distribuição por setores (\%)

Fonte: CEBC (2017) - Gráfico elabora pelo autor.

\section{CONSIDERAÇÕES FINAIS}

Compreende-se a partir do presente estudo que, o território fluminense, ao longo do século XX, apresentou uma trajetória caracterizada pela diminuição de sua participação na produção industrial brasileira e redução de sua contribuição no PIB nacional. Tendo que aguardar a década de 1990, para assistir um conjunto de mudanças atreladas à implantação de novas atividades produtivas, a realização de novos investimentos em infraestrutura e as alterações nas bases de suas economias regionais que, por conseguinte, desencadearam o processo de reestruturação produtiva do território. 
Na atual fase do processo de globalização e intensificação da circulação de capital, o estado do Rio de Janeiro, enquanto recipiendário de investimentos assistiu, mais recentemente, o influxo do capital sínico em seu território. Assim, o território fluminense, entre os anos 2007 e 2016, foi o destino de, aproximadamente, US\$21,9 bilhões de investimentos chineses realizados no Brasil, o que corresponde a $45 \%$, dos US $\$ 46,1$ bilhões, sob a forma de IED oriundo da República Popular da China confirmados no país, entre 2007-2016.

O ingresso dos investimentos chineses no Brasil, no recorte temporal mencionado, equivaleu à implantação de oitenta e oito projetos. Entre esses projetos, setenta e oito foram realizados em diferentes Unidades Federativas do país, enquanto, dez foram implantados no território fluminense, concentrando-se no setor de energia, apesar de outros setores como o siderúrgico, infraestrutura, ferroviário, informática e automotivo também se apresentarem como setores receptores desse montante de capital.

Nota-se ainda, que a estrutura da propriedade dos investimentos chineses é predominantemente estatal, dada a atuação, em oito desses projetos, realizada por grandes corporações chinesas, como por exemplo, a Sinopec Repsol Brasil, a Sinochem Statoil, a Wuhan Iron Stell Group Co., a China Northern Railway, a China National Petroleum Corporation, a China National Offshore Oil Corporation, a State Grid, a China Communications Construction Company. Enquanto os menores volumes de capital investido no estado, correspondem à implantação de dois projetos de empresas privadas chinesas nos setores automotivo e informática, através da atuação, respectivamente, da CR Zong-Shen e da Qihoo, cujo determinante do investimento foi a busca por mercado. As grandes corporações chinesas mencionadas que se concentram, destacadamente, nos setores de energia, siderurgia, infraestrutura e ferroviário, tem como principal determinante dos seus investimentos no território fluminense a busca por recursos, embora a busca por mercado se projete enquanto determinante dos investimentos realizados pelas empresas China Northern Railway e State Grid.

\section{REFERÊNCIAS}


ALVES, A. G. de M. P. As Relações de Investimentos Diretos entre a China e os Países de seu Entorno. In: ALVES, A. G. de M. P. (Org.) Os BRICS e seus vizinhos: investimento direto estrangeiro. Brasília: Ipea, 2014.

ANDREWS, Christina W. Da década perdida à reforma gerencial: 1980-1998. In.: ANDREWS, Christina W.; BARIAN, Edson (orgs.). Administração Pública no Brasil, Breve História Política. São Paulo: Editora Unifesp, 2010, pp. 85-118.

BUCKLEY, P. J. et al. Historic and Emergent Trends in Chinese Outward Direct Investment. In: BUCKLEY, P. J. Foreign Direct Investment, China and the World Economy. Palgrave Macmillan, 2010.

CASTRO, Lavinia Barros de. Privatização, Abertura e Desindexação: A Primeira Metade dos anos 1990 (1990-1994). In.: GIAMBAGI, F. el al (orgs.). Economia Brasileira Contemporânea (1945-2015 - $3^{\text {a }}$ ed. - Rio de Janeiro: Elsevier, 2016.

CEBC. Investimentos chineses no Brasil: uma nova fase da relação Brasil-China. Rio de Janeiro, 2011.

Uma análise dos investimentos chineses no Brasil: 2007-2012. Rio de Janeiro, 2013.

Boletim de Investimentos Chineses no Brasil (2012-2013). Rio de Janeiro, 2014.

Oportunidades de Comércio e Investimento na China para setores selecionados. CEBC, Rio de Janeiro, 2015.

Investimentos chineses no Brasil: 2014-2015. CEBC, Rio de Janeiro, 2016.

Investimentos chineses no Brasil: 2016. CEBC, Rio de Janeiro, 2017.

CEPAL, Documento informativo - La inversión Extranjera Directa en América Latina y el Caribe. 2017. Disponível em: $<$ httprepositorio.cepal.orgbitstreamhandle11362420234S1700431_es.pdf>. Acesso em: 01 set 2017.

GIAMBIAGI, Fabio. Estabilização, reformas e desequilíbrios macroeconômicos: os anos FHC (1995-2002). In.: GIAMBAGI, F. el al (orgs.). In.: GIAMBAGI, F. el al (orgs.). Economia Brasileira Contemporânea (1945-2015 - $3^{\text {a }}$ ed. - Rio de Janeiro: Elsevier, 2016.

IPEA, Internacionalização das Empresas Chinesas: as Prioridades do Investimento Direto Chinês no Mundo. Comunicados do IPEA n. 84, 2011.

KISSINGER, H. Sobre a China. Rio de Janeiro: Objetiva, 2011.

LACERDA, Antônio Corrêa de. Notas sobre as características e o perfil dos fluxos recentes de investimentos diretos estrangeiros na economia brasileira. In.: O Brasil e os desafios da globalização / Pedro da Motta Veiga, organizador. - Rio de Janeiro: Relume-Dumará; São Paulo: SOBEET, 2000. pp. 193-207.

MELO, H. P. A trajetória da industrialização do Rio de Janeiro. In: AMÉRICO FREIRE, A.; SARMENTO, C.E.; MOTA, M.S. (Org.) Um Estado em questão: os 25 anos do Rio de Janeiro. Rio de Janeiro: FGV, 2001. p. 219-248.

MIRANDA, José Carlos e TAVARES, Maria da C. Brasil: estratégias de conglomeração. In.: Estados e moedas no desenvolvimento das nações. FIORI, José Luís (org.). Petrópolis, RJ: Vozes, 1999. pp. 327-350.

OLIVEIRA, A. L. S. de. O investimento direto das empresas chinesas no Brasil - um estudo exploratório. (Dissertação/COPPE/UFRJ). Rio de Janeiro, 2012.

OLIVEIRA, F. J. G.. Políticas territoriais e integração do "novo" território do estado do Rio de Janeiro. In: EGLER, T. T. C e TAVARES, H. M. (Orgs.). Política Pública, rede social e território. Rio de Janeiro: Letra Capital, 2012. 
OLIVEIRA, H. A. de. Brasil e China Cooperação Sul-Sul e Parceria Estratégica. Belo Horizonte: Fino Traço, 2012.

SILVA, R. D. Indústria e desenvolvimento regional no Rio de Janeiro. Rio de Janeiro: FGV, Editora, 2012.

SANTOS, M. O retorno do território. In.: Da Totalidade ao Lugar. São Paulo: Edusp, 2012, p. 137-144.

SÖDERSTEN, B. Economia Internacional. Rio de Janeiro: Interciência, 1979.

SOJA, Edward. Uma concepção materialista da espacialidade. In: Becker, Berta; COSTA, Rogério Haesbaert da; SILVEIRA, Carmen. Abordagens políticas da espacialidade. Rio de Janeiro: UFRJ, Departamento de Geografia / Programa de pós-graduação: 1983.

TENÓRIO, Fernando G. e SARAIVA, Enrique J. Escorços sobre gestão pública e gestão social. In: MARTINS, Paulo E. Matos e PIERANTI, Octavio Penna (Orgs.). Estado e gestão pública: visões do Brasil contemporâneo. 2. ed. Rio de Janeiro: Editora FGV, 2006.

TERRA, D. C. et al. A Reestruturação econômica e territorial do Norte Fluminense. In: MONIÉ. F. e BINSZTOK, J. (Orgs.). Rio de Janeiro: Mauad, 2012. 